\title{
Physical and functional properties of Indian squid (Loligo duvauceli) and cuttlefish (Sepia latimanus) ink powder
}

\author{
Ahamed, A.R.G.B., Hossain, M.P., Antora, R.A. and *Rabeta M.S \\ Food Technology Division, School of Industrial Technology, Universiti Sains Malaysia, 11800 Minden, \\ Penang, Malaysia.
}

\begin{abstract}
Article history:
Received: 6 March 2018

Received in revised form: 29

March 2018

Accepted: 31 March 2018

Available Online: 6 April 2018
\end{abstract}

\section{Keywords:}

Physical properties,

Functional properties,

Squid,

Cuttlefish,

Ink powder

\section{DOI:}

https://doi.org/10.26656/fr.2017.2(4).070

\begin{abstract}
This study aimed to compare the physical and functional properties of Indian squid (Loligo duvauceli) and cuttlefish (Sepia latimanus) ink powders. Indian squid and cuttlefish are common major sources of seafood products available in Malaysia. However, the inks of these cephalopods are considered waste products. Inks were removed from squids, freezedried, and ground into powder form. The color, $\mathrm{pH}$, water activity, bulk and tapped densities, emulsifying activity and stability, viscosity, water solubility and microscopic study were examined. The mean $L^{*}$ value of cuttlefish ink was $14.27 \pm 0.010$. Squid ink was slightly darker in color $(12.21 \pm 0.005)$. The physical properties of squid and cuttlefish ink were $\mathrm{pH}(6.48 \pm 0.01,7.26 \pm 0.02)$, water activity $(0.091 \pm 0.006,0.166 \pm 0.003)$, and bulk and tapped densities $\left(24.650 \pm 0.02,20.591 \pm 1.78 \mathrm{~g} / \mathrm{m}^{3}\right)$. The functional properties of both squid and cuttlefish were emulsion activity $(15.38 \pm 2.67,11.88 \pm 0.23)$, emulsion stability $(56.56 \pm 30.45,39.09 \pm 2.91)$, viscosity $(3.07 \pm 0.051 \mathrm{mPa}, 2.96 \pm 0.057 \mathrm{mPa})$, and water solubility index $(17.12 \pm 0.01 \%, 10.51 \pm 0.01 \%)$. Cuttlefish ink powder is better than squid ink powder because it possessed most of the properties satisfying industrial requirements (emulsion activity, emulsion stability, viscosity, water solubility, bulk and tapped densities). This ink can also be used as a natural emulsifier in food applications.
\end{abstract}

\section{Introduction}

Huge innovation opportunities exist in using an underutilized by-product to create new healthy products for consumers. In the $21^{\text {st }}$ century, consumer's interest in healthy eating is shifting towards the potential health benefits beyond basic nutrition. The beyond functions are not performed by nutrients in foods rather by other components present in them (Tee, 2013). Generally, functional foods look the same to conventional foods (Cencic and Chingwaru, 2010). Moreover, functional foods should be, or look like, a traditional food and must be part of our daily diet (European Commission, 2010).

Cephalopods ink is a by-product of seafood processing and can be used as a food additive in food processing (Sasaki et al., 1997). In order to prevent from their predator, squid and cuttlefish have to release a black ink which can camouflage the surrounding and left the place (Derby, 2014). Cephalopods are the most important marine fishery resources all over the world, particularly in Malaysia, in terms of economic value and domestic consumption. Every year, around 70 to 80 thousand tons of squid and cuttlefish are caught and processed in Malaysia while those ink sacs are discarded and thrown as wastage (Department of Fisheries, Malaysia, 2015). For a long period of time, people are throwing food wastes without knowing their benefits. Among these waste products, some are useful due to their health benefits and can be utilized as food additives when applied in food processing.

Traditionally, in eastern peninsular Malaysia, squid ink extract is added to cook squid dishes to increase the flavor of the dish and for other purposes. However, insufficient awareness of the functional value of squid ink restricts the full utilization of squid ink in the food industry. In Japan, squid ink has been utilized as a traditional component in food products. For example, cuttlefish ink exhibits the antiseptic effect on 'Ikashiokara', which is a cured cuttlefish meat produced in Japan (Takai et al., 1992). To date, there is no information on the physical and functional properties of squid and cuttlefish ink in Malaysia. The need to carry out this study was to address this gap as well as to propose the potentiality of squid and cuttlefish ink as a food ingredient. This study can lead to the innovation of by-product for further healthy and hygienic product 
development and commercialization. The success of the study will decrease the by-products of these resources as well as pollution of the environment.

\section{Material and methods}

\subsection{Collection and sample preparation}

Indian squid (Loligo duvauceli) and cuttlefish (Sepia latimanus) were purchased in Taman Tun Sardon Wet Market near Gelugor, Penang, Malaysia during early of November 2016 until the end of February 2017. The samples were sent to Dr. Amir Shah Ruddin bin Md. Sah from School of Biology, USM, for species identification. The samples were selected based on same size and physical appearance and kept in a large container with ice cubes to maintain freshness of squid and cuttlefish. Ink glands were manually removed from the viscera of freshly obtained squids. The ink glands were placed in a clean plastic container with a thin layer of approximately $2.0 \pm 0.5 \mathrm{~cm}$. The ink was pressed and squeezed out from the ink glands by using a spoon and 30-mesh sieve. After that, the ink was frozen using a blast freezer at $-18^{\circ} \mathrm{C}$ for 3 hours until it freezes completely. The frozen ink was transferred to a freeze dryer for 2 days (Labconco laboratory freeze dryer) to drain out moisture completely from the sample. The freeze-dried ink was grounded to fine powder using an electric blender (Retsch ZM 200). The sample powder was then packed in polyethylene bags and kept in an airtight plastic container. The container was covered with aluminum foil to prevent light from penetrating through it. The samples were labeled according to species and stored in a freezer at $-20^{\circ} \mathrm{C}$ before analyses were carried out.

\subsection{Analysis of physical properties}

\subsubsection{Color}

The color of squid ink powder was analyzed using colorimeter (Model Minolta Spectrophotometer CM3500D, Osaka, Japan). The colorimeter must be calibrated first with zero calibration plate and followed by white calibration plate. Squid ink sample was placed into the petri dish, which was specifically used for powdered sample in color analysis. The measurement was repeated thrice or seven times to obtain the average of measurement of the sample. Each time, the Petri dish with the sample was shaken lightly with horizontal movements to shuffle the contents to obtain a more accurate result. The parameters were $\mathrm{L}^{*}$ (lightness), a* (redness) and $\mathrm{b}^{*}$ (yellowness) of the squid ink powder was determined. The color was expressed using the polar coordinates $\mathrm{L}^{*} \mathrm{C}^{*} \mathrm{~h}$, where $\mathrm{L}^{*}$ is the lightness, $\mathrm{C}^{*}$ is the chroma, and $\mathrm{h}$ is the hue angle.

\subsubsection{Water activity}

The measurement of water activity $\left(\mathrm{a}_{\mathrm{w}}\right)$ for squid ink powder was obtained using water activity measurement device (Aqualab Series 3 TE, USA). The analysis was performed in triplicate for each sample, and the average measurement was used to express the water activity of each sample.

\subsection{3 $\mathrm{pH}$ determination}

The $\mathrm{pH}$ value of each ink sample was determined using $\mathrm{pH}$ meter. About $2 \mathrm{~g}$ of sample was mixed with 10 $\mathrm{ml}$ deionized water at $20^{\circ} \mathrm{C}$. The $\mathrm{pH}$ meter was calibrated first with standard buffer $\mathrm{pH} 7$ and 4 .

\subsubsection{Bulk and tapped density}

The bulk density of the sample was determined according to the method of Sousa et al. (2013). Approximately $10 \mathrm{~g}$ of sample was placed into a $25 \mathrm{ml}$ graduated cylinder and tapped for 10 times. This analysis was repeated thrice for each sample. The volume of sample was measured as well as the bulk density was calculated by this formula :

$$
\text { Bulk density }=\frac{\text { Weight of sample }(\mathrm{g})}{\text { Volume of sample }(\mathrm{mL})}
$$

\subsection{Analysis of functional properties}

\subsubsection{Water solubility index}

Water solubility index (WSI) was determined according to Amza et al. (2011) with slight modification. About $2.5 \mathrm{~g}$ of sample and $30 \mathrm{ml}$ of distilled water were added to a $50 \mathrm{ml}$ centrifuge tube and mixed vigorously by vortex. Then, the suspension was incubated in water bath at $60^{\circ} \mathrm{C}$ for 20 minutes. The samples were then centrifuged at $4000 \mathrm{x} g$ for 10 minutes. The supernatant was collected in a pre-weighed beaker, whereas the residue was dried and weighed after the water was evaporated at $105^{\circ} \mathrm{C}$ for 24 hours. The percentage of residue with respect to the amount of squid ink powder used in this analysis was taken as water solubility. Water solubility index (WSI) was calculated as the equation below

$$
\text { WSI }(\%)=\frac{\text { Weight of the supernatant }(\mathrm{g})}{\text { Initial weight of sample }(\mathrm{g})} \times 100
$$

\subsubsection{Viscosity}

The viscosity of squid ink was determined by following the method of Sathe and Salunkhe (1981) with slight modification. Three grams of squid ink powder was added to $100 \mathrm{ml}$ of distilled water and stirred magnetically for 2 hours at room temperature (mention). Then, the viscosity of the sample was measured by an Ostwald type viscometer. 


\subsubsection{Emulsification}

The emulsifying properties of squid ink were determined according to Nagarajan et al. (2012). The squid ink powder was added to distilled water to prepare $1 \%, 2 \%$ and $3 \%$ of squid ink solution. Approximately 6 $\mathrm{ml}$ of protein solution and $2 \mathrm{ml}$ of soybean oil were mixed and homogenized at 20,000 rpm for $1 \mathrm{~min}$ by T25 IKA homogenizer. About 50 ul of the emulsion was mixed with $5 \mathrm{ml}$ of $0.1 \%$ sodium dodecyl sulfate solution. The absorbance of the mixture was measured by UV visible spectrophotometer (Model Uvmini-1240) at $500 \mathrm{~nm}$. The emulsifying absorbance index (EAI) is the absorbance value of the emulsion, whereas the emulsifying stability index (ESI) was calculated by the equation is given:

$$
\mathrm{EAI}=\frac{2 \times 2.303 \times \mathrm{A}_{0}}{0.25 \times \text { sample weight }(\mathrm{g})} \quad \mathrm{ESI}=\frac{\mathrm{A}_{0}}{\mathrm{~A}_{0}-\mathrm{A}_{10}}
$$

where $\mathrm{A}_{0}=$ Absorbance values of the squid ink emulsion measured at $0 \mathrm{~min} ; \mathrm{A}_{10}=\mathrm{Absorbance}$ values of the squid ink emulsion measured at $10 \mathrm{~min}$.

The test in was carried out in triplicate for each sample and the average mean values.

\subsection{Statistical analysis}

The results were analyzed in triplicate, mean value and standard deviation, where $n=3$. One-way analysis of variance followed by the t-test was used to compare significant differences between means at the 5\% significance level. Data analysis was conducted by using statistical software IBM SPSS version 22.0 for the Windows (SPSS, Inc., Chicago, II., USA).

\section{Result and discussion}

\subsection{Color}

As shown in Table 1, all obtained color values displayed significant difference $(\mathrm{p}<0.05)$ between squid and cuttlefish ink powders. When the $L^{*}$ value increased, the sample became light-colored. The mean $L^{*}$ value of cuttlefish ink was $14.27 \pm 0.010$. Squid ink was slightly darker in color $(12.21 \pm 0.005)$ than that of cuttlefish squid ink. $L^{*}$ is the vertical axis representing lightness; a score of 100 represents an ideal white sample, and 0 is an ideal black sample (Gilchrist and Nobbs, 2017). Analysis results indicated that the squid ink powder displayed darker color, duller appearance, and more red and yellow colors compared with those of cuttlefish ink (Ramos et al., 2011). The melanogenesis reaction occurred in presence of melanogenic enzymes as tyrosinase, dopachrome rearranging enzyme and a peroxidase by which melanin pigment is produced is the reason of dark color of squid and cuttlefish ink (Jiménez-Cervantes et al., 1994). High amount of enzymes presents in squid ink helped to produced more melanin resulted in darker color in squid ink (Palumbo, 2003). Additionally, the ink powder color plays an important role as a natural food coloring agent in different food application. Therefore, cephalopod ink can produce distinct foods with a distinct color, which may be different from that of normal food products in terms of appearance. The physical property that mostly determines the quality of any food and beverage product is its appearance.

The color and appearance of food products, as first impressions, are typically the primary indicators of perceived quality (Gambaro et al., 2001). Squid ink powder showed higher $a^{*}(0.67 \pm 0.035)$ mean and $b^{*}$ $(1.51 \pm 0.045)$ mean values than those of mean values for cuttlefish ink powder $\left(a^{*}=0.38 \pm 0.030 ; b^{*}=\right.$ $-0.123 \pm 0.023)$. In addition, $a^{*}$ is a chromatic value between -120 and +120 , that is, from green to red; $b^{*}$ is a chromatic value between -120 and +120 , that is, from blue to yellow (Tarlak et al., 2016). Positive $a^{*}$ and $b^{*}$ values for the squid ink powder exhibited an orange hue. The $b^{*}$ values result in yellow-blue character, with positive values for yellow shades and negative for blues (Broadbent, 2017). Therefore, the cuttlefish ink powder color is better than that of the squid ink powder.

\section{$3.2 \mathrm{pH}$ determination}

As shown in Table 2, $\mathrm{pH}$ analysis results indicated a significant difference between squid and cuttlefish ink powders $(\mathrm{p}<0.05)$. On the basis of this result, the $\mathrm{pH}$ value for squid ink was $6.45 \pm 0.01 \%$, which was slightly acidic compared with that of the cuttlefish ink, which was $7.26 \pm 0.02 \%$ (slightly alkaline). Preventing microbial growth is our major concern in this study. $\mathrm{pH}$ is a common property that measures the acidity or alkalinity of a solution. This property is a remarkably important and intrinsic factor affecting the survival and growth of microorganisms in squid and cuttlefish ink powders. The $\mathrm{pH}$ ranges from 0 to 14 , where $\mathrm{pH} 7$ is considered

Table 1. Colour analysis for cuttlefish and squid ink powder

\begin{tabular}{cccccc}
\hline \multirow{2}{*}{ Sample } & \multicolumn{5}{c}{ Colour Coordinates } \\
\cline { 2 - 6 } & $\mathrm{L}^{*}$ & $\mathrm{a}^{*}$ & $\mathrm{~b}^{*}$ & Chroma & Hue $^{\mathrm{o}}$ \\
\hline Cuttlefish & $14.27 \pm 0.010^{\mathrm{a}}$ & $0.38 \pm 0.030^{\mathrm{a}}$ & $-0.123 \pm 0.023^{\mathrm{a}}$ & $0.403 \pm 0.030^{\mathrm{a}}$ & $339.73 \pm 4.53^{\mathrm{b}}$ \\
Squid & $12.21 \pm 0.005^{\mathrm{b}}$ & $0.67 \pm 0.035^{\mathrm{b}}$ & $1.51 \pm 0.045^{\mathrm{b}}$ & $1.66 \pm 0.026^{\mathrm{b}}$ & $66.24 \pm 1.82^{\mathrm{b}}$ \\
\hline
\end{tabular}

Data is expressed as mean \pm standard deviation of triplicate determination of t-test. Means in column sharing the different superscript letter are significantly different $(\mathrm{p}<0.05)$. 
neutral.

Measuring the $\mathrm{pH}$ of each food ingredient may be necessary to assess whether any component can support pathogenic growth. In addition, $\mathrm{pH}$ measurement is useful in evaluating the quality of squid and cuttlefish ink powders for further processing (Food Safety and Standard Authority of India, 2012). Squid ink is better than cuttlefish ink powder due to low $\mathrm{pH}$ value.

Table 2. The result of $\mathrm{pH}$ analysis, bulk and tapped density for squid and cuttlefish ink powder

\begin{tabular}{cccc}
\hline Sample & $\mathrm{pH}$ & $\begin{array}{c}\text { Bulk density } \\
(\mathrm{g} / \mathrm{ml})\end{array}$ & $\begin{array}{c}\text { Tapped } \\
\text { density }(\mathrm{g} / \mathrm{ml})\end{array}$ \\
\hline Cuttlefish & $7.26 \pm 0.02^{\mathrm{a}}$ & $18.5 \pm 0.50^{\mathrm{a}}$ & $20.591 \pm 1.78^{\mathrm{a}}$ \\
Squid & $6.45 \pm 0.01^{\mathrm{b}}$ & $18.33 \pm 0.29^{\mathrm{a}}$ & $24.650 \pm 0.02^{\mathrm{b}}$ \\
\hline
\end{tabular}

Data is expressed as mean \pm standard deviation of triplicate determination of t-test. Means in column sharing the different superscript letter are significantly different $(\mathrm{p}<0.05)$.

\subsection{Bulk and tapped densities}

As shown in Table 2, the bulk density of squid and cuttlefish ink powder with $18.33 \pm 0.29$ and $18.5 \pm 0.50$, respectively, showed no significant difference $(\mathrm{p}>0.05)$. For the tapped density, a significant difference $(p<0.05)$ was observed between squid and cuttlefish ink powders at $24.65 \pm 0.2$ and $20.591 \pm 1.78$, respectively. Both samples showed the bulk densities of ink powders under loose and tapped packing conditions. Loose packing is the condition observed by pouring a powder sample into a vessel without any consolidation. Tapped packing is the condition observed when the vessel containing the powder sample is repeatedly dropped with a consistent drop rate from a specific distance until the expected apparent volume of the sample in the vessel remains unchanged (European Medicines Agency, 2013).

Squid ink powder showed higher tapped density than that of cuttlefish ink powder. Both bulk and tapped densities are important for powder flow evaluation. Powder flow should be analyzed in pharmaceutical and cosmeceutical industries (Rakhi et al., 2008). The bulking property of a powder is dependent on factors during sample preparation, treatment, and storage (World Health Organization, 2012). The powder cohesiveness influences the flow of powders and causes difficulty in powder flow (Rakhi et al., 2008). Compaction process enhances the increased density of the solid powder, and a low amount of pore spaces exists between solid compounds (Birchal 2005). The Hausner ratio for squid ink and cuttlefish are 1.344 and 1.11 that means cuttlefish ink will show excellent flow character while squid ink will show passable flow character (Carr, 1965).

\subsection{Water activity $\left(a_{w}\right)$}

A significant difference in $\mathrm{a}_{\mathrm{w}}$ was observed between squid and cuttlefish ink powders $(\mathrm{p}<0.05)$ (Table 3 ). Results showed that the $a_{w}$ of squid and cuttlefish ink powder was relatively low, with values below 0.2 , namely, 0.091 and 0.166, respectively. Lund et al. (2000) described that food with low $\mathrm{a}_{\mathrm{w}}$ is considered safe from foodborne pathogens because the optimum $a_{w}$ for the growth of these pathogens is over 0.98 . This optimum $a_{w}$ indicated the increased product stability and stable shelflife under ambient storage conditions. $\mathrm{a}_{\mathrm{w}}$ is a physical property that exerts direct implication for the microbial safety of food by predicting the growth of bacteria, yeasts, and molds. The $\mathrm{a}_{\mathrm{w}}$ ranges from 0 to 1 , in which 0.2 is considered dry food, and 0.99 is moist food.

\subsection{Water solubility index (WSI)}

Cuttlefish and squid ink powders showed a WSI of 17.1 and 10.51, respectively (Table 3). Zayas (1997a) stated that a high WSI value displays good dispersibility of protein molecules and results in the formation of finely dispersed colloidal systems. Protein solubility is affected by $\mathrm{pH}$, solvent type, ionic strength, temperature, and processing condition. The solubility degree is increased when the electrostatic repulsion between the molecules is higher than the hydrophobic interaction (Zayas, 1997b). Solubility is one of the most important functional properties of protein used in liquid food and beverages. WSI measures the sample protein content that dissolves in water.

Table 3. Water activity and water solubility index (WSI) for squid and cuttlefish ink powder.

\begin{tabular}{ccc}
\hline Sample & Water activity $\left(\mathrm{A}_{\mathrm{w}}\right)$ & WSI $(\%)$ \\
\hline Cuttlefish & $0.166 \pm 0.003^{\mathrm{a}}$ & $17.12 \pm 0.01^{\mathrm{a}}$ \\
Squid & $0.091 \pm 0.006^{\mathrm{b}}$ & $10.51 \pm 0.01^{\mathrm{b}}$
\end{tabular}

Data is expressed as mean \pm standard deviation of triplicate determination of t-test. Means in column sharing the different superscript letter are significantly different $(\mathrm{p}<0.05)$.

\subsection{Viscosity}

Table 4 showed that cuttlefish ink powder displayed a mean value of 3.07 , which indicated higher viscosity than squid ink (2.96). Protein stability is due to several factors, such as temperature, $\mathrm{pH}$, and concentration of substrate and enzyme used. The unfolding and denaturation of protein structure resulted in the formation of gel-like structure and increase the viscosity of protein solution.

\subsection{Emulsification properties}

The emulsion activity of cuttlefish and squid inks showed the highest mean value of 15.38 and 11.88 , respectively (Table 4). In terms of emulsion stability, 
cuttlefish ink displayed a higher mean value of $56.56 \%$ than that of squid ink $(39.09 \%)$. This result may be due to the different protein contents in squid and cuttlefish ink. The emulsion stability value is based on the electrostatic repulsion between protein molecules. Moreover, this result showed that these inks possessed good stability against flocculation and droplet coalescence because the range of the attractive forces acting between the droplets decreases with decreasing particle size, whereas the range of the steric repulsion is slightly dependent on particle size (Qian and McClements, 2011).

Table 4. Viscosity, Emulsion activity index (EAI) and Emulsion stability index (ESI) for squid and cuttlefish ink powder

\begin{tabular}{cccc}
\hline Sample & $\begin{array}{c}\text { Viscosity } \\
(\mathrm{mPa} . \mathrm{s})\end{array}$ & EAI (min) & ESI (min) \\
\hline Cuttlefish & $3.07 \pm 0.051^{\mathrm{a}}$ & $15.38 \pm 2.67^{\mathrm{a}}$ & $56.56 \pm 0.45^{\mathrm{a}}$ \\
Squid & $2.96 \pm 0.057^{\mathrm{a}}$ & $11.880 .23^{\mathrm{b}}$ & $39.09 \pm 2.91^{\mathrm{b}}$ \\
\hline
\end{tabular}

Data is expressed as mean \pm standard deviation of triplicate determination of t-test. Means in column sharing the different superscript letter are significantly different $(\mathrm{p}<0.05)$.

\section{Conclusion}

On the basis of the obtained data, we concluded that squid and cuttlefish inks possess different physical and functional properties. The squid ink showed lower aw, higher tapped density, and better oil absorption capacity and foaming ability than those of the cuttlefish ink. Conversely, cuttlefish ink presented higher bulk density and viscosity and better water absorption ability, water solubility, and emulsifying ability than those of the squid ink. Overall, cuttlefish ink is better than squid ink because the former possesses most of the properties satisfying the industrial requirements. Cuttlefish ink can also be used as a natural emulsifier and foaming agent in food applications. Although squid and cuttlefish inks are considered byproducts, they can be incorporated in the food industry, especially in a baking industry as a natural food coloring and a functional ingredient.

\section{Conflict of interest}

We declare that we have no conflict of interest.

\section{Acknowledgment}

The research work is supported by Food Technology Division, School of Industrial Technology, Universiti Sains Malaysia.

\section{References}

Amza, T., Amadou, I., Kamara, M.T., Zhu, K.X. and
Zhou, H.M. (2011). Nutritional and functional characteristics of gingerbread plum (Neocarya macrophylla): an underutilized oil seed. Grasas y Aceites, 62(3), 290-298. https://doi.org/10.3989/ gya.089910

Birchal, V.S., Passos, M.L., Wildhagen, G.R. and Mujumdar, A.S. (2005). Effect of spray-dryer operating variables on the whole milk powder quality. Drying Technology, 23(3), 611-636. https:// doi.org/10.1081/DRT-200054153

Broadbent, A.D. (2017). Colorimetry Methods. In Lindon, J., Tranter, G.E. and Koppenaal, D. (Eds). Encyclopedia of Spectroscopy and Spectrometry, $3^{\text {rd }}$ ed. USA: Elsevier. https://doi.org/10.1016/B978-012-803224-4.00014-5

Carr, R.L. (1965). Evaluating Flow Properties of Solids. Chemical Engineering Journal, 72, 163-168

Cencic, A. and Chingwaru, W. (2010). The role of functional foods, nutraceuticals, and food supplements in intestinal health. Nutrients, 2(6), 611625. https://doi.org/10.3390/nu2060611

Department of Fisheries, Malaysia (2015). Annual Fisheries Statistics. Retrieved on May 1, 2017 from Department of Fisheries website: http:// www.dof.gov.my

Derby, C.D. (2014). Cephalopod ink: production, chemistry, functions, and applications. Marine Drugs, 12(5), 2700-2730. https://doi.org/10.3390/ md12052700

European Commission. (2010). What are functional foods? In Functional Foods. Luxembourg: Publications Office of the European Union.

European Medicines Agency. (2013). ICH guideline Q4B annex 13 to note for evaluation and recommendation of pharmacopoeial texts for use in the ICH regions on bulk density and tapped density of powders. (EMA/CHMP/ICH/405290/2010). United Kingdom: European Medicines Agency.

Food Safety and Standard Authority of India. (2012). Manual of Methods of Analysis of Food. India: Ministry of Health and Family Welfare Government of India, Delhi.

Gambaro, A., Gimenez, A. and Burgueño, J. (2001). Sensory and instrumental evaluation of strawberry yogurt color. Journal of Sensory Studies, 16(1), 1122. https://doi.org/10.1111/j.1745459X.2001.tb00287.x

Gilchrist, A. and Nobbs, J. (2017). Colorimetry Theory. In Lindon, J., Tranter, G.E. and Koppenaal, D. (Eds). Encyclopedia of Spectroscopy and Spectrometry, $3^{\text {rd }}$ ed. USA: Elsevier. https://doi.org/10.1016/B978-012-803224-4.00124-2 
Jiménez-Cervantes, C., Solano, F., Kobayashi, T, Urabe, K., Hearing, V.J., Lozano, J.A. and García-Borron, C. (1994). A New Enzymatic Function in the Melanogenic Pathway. The Journal Of Biological Chemist, 269(27), 17993-18001.

Lund, B.M., Baird-Parker, T.C. and Goul, G.W. (2000). The Microbiological Safety and Quality of Foods. Gaithersburg, Maryland: Aspen Publishers.

Nagarajan, M., Benjakul, S., Prodpran, T., Songtipya, P. and Kishimura, H. (2012). Characteristics and functional properties of gelatin from splendid squid (Loligo formosana) skin as affected by extraction temperatures. Food Hydrocolloids, 29(2),389-397. https://doi.org/10.1016/j.foodhyd.2012.04.001

Palumbo, A. (2003). Melanogenesis in the ink gland of Sepia officinalis. Pigment Cell Research, 16, 517522. 0749.2003.00080.x https://doi.org/10.1034/j.1600-

Qian, C. and Mcclements, D.J. (2011). Formation of nano-emulsions stabilized by model food-grade emulsifiers using high-pressure homogenization: factors affecting particle size. Food Hydrocolloids, 25(5),1000-1008. https://doi.org/10.1016/ j.foodhyd.2010.09.017

Rakhi, B.S., Mobin, A.T. and Mansoor, A.K. (2008). Comparative Evaluation of Flow for Pharmaceutical Powders and Granules. AAPS PharmSciTech, 9(1), 250-258. https://doi.org/10.1208/s12249-008-9046-8

Ramos, L., Penas, M., Remeseiro, B., Mosquera, A., Barreira, N. and Yebra-Pimentel, E. (2011). Texture and colour analysis for the automatic classification of the eye lipid layer. Advances in Computational Intelligence, 66-73. https://doi.org/10.1007/978-3642-21498-1_9

Sasaki, J.I., Ishita, K., Takaya, Y., Uchisawa, H. and Matsue, H. (1997). Anti-tumor activity of squid ink. Journal of Nutritional Science and Vitaminology, 43(4), 455-461. https:// doi.org/10.3177/jnsv.43.455

Sathe, S.K. and Salunkhe, D.K. (1981). Functional properties of the great northern bean (Phaseolus vulgaris L.) proteins: emulsion, foaming, viscosity, and gelation properties. Journal of Food Science, 46 (1), 71-81. https://doi.org/10.1111/j.13652621.1981.tb14533.x

Sousa, E., Silva, J.P., Splendor, D. and Sousa, L.J.M. (2013). Note on the measurement of bulk density and tapped density of powders according to the European Pharmacopeia. AAPS Pharm Sci Tech 14(3), 10981100. https://doi.org/10.1208/s12249-013-9994-5

Takai, M., Kawai, Y., Inoue, N. and Shinano, H. (1992). Comparative studies on microbiological and chemical characteristics of" ika-shiokara akazukuri" and" ika-shiokara kurozukuri". Nippon Suisan Gakkaishi 58, 2373-2373. https://doi.org/10.2331/ suisan.58.2373

Tarlak, F., Ozdemir, M. and Melikoglu, M. (2016). Computer vision system approach in colour measurements of foods: Part II. validation of methodology with real foods. Food Science and Technology, 36(3), 499-504. https:// doi.org/10.1590/1678-457X.02616

Tee, E.S. (2013). Functional foods for health promotion. Retrieved from Jabatan Kesihatan Negeri Kelantan: http://jknkelantan.moh.gov.my

World Health Organization (WHO). (2012). Bulk Density and Tapped Density of Powders. Geneva: WHO.

Zayas, J.F. (Ed.) (1997a). Solubility of proteins. In Functionality of proteins in food, p. 6-75. Berlin: Springer. https://doi.org/10.1007/978-3-642-591167_2

Zayas, J.F. (Ed.) (1997b). Emulsifying properties of proteins. In Functionality of proteins in food, p. 134227. Berlin: Springer. https://doi.org/10.1007/978-3642-59116-7_4 